\title{
Architecture as Art Object: The Analysis of One of the Flows of Contemporary Architecture
}

\author{
Nina Konovalova, ${ }^{1, *}$ \\ ${ }^{1}$ Scientific Research Institute of the Theory and History of Architecture and Urban Planning, Branch of the \\ Federal State Budget Institution "Central Scientific-Research and Project Institute of the Construction Ministry \\ of Russia”, Moscow, Russia \\ *Corresponding author. Email: phuekirjuko@mail.ru
}

\begin{abstract}
In the beginning of XXI century a fundamental formalized tendency in contemporary architecture might be discovered. An artistic image of a building does not only take the foreground, but moreover becomes more essential than its functions and other architectural aspects. The change of priorities in perception and evaluation of contemporary architecture is taking its place. It affects temporary objects of architecture in the first place, which are primarily created and perceived as art objects. Nevertheless, buildings created for long-term usage as well often bring their artistic components to the foreground - color theory, texture, symbolism. In the article the attempt is made to trace the underlined tendency and analyze possible outcomes.
\end{abstract}

Keywords: Contemporary architecture, Artistic image, Art object, World's fair, Serpentine art-gallery.

\section{INTRODUCTION}

Recent decades saw a trend towards significant dominance of the artistic component over all other aspects of architectural objects in contemporary architecture. This trend in contemporary architecture could be referred to as "styling design" when the utilitarian function of the architecture translates into the function of the art object. In this case the shift in emphasis occurs at the level of both the creator of a piece of contemporary architecture and the consumer, represented by general public who use, perceive and evaluate it.

It is possible to single out a number of types of architectural edifices which are prone to exercise the role of the art object due to the essence of their shaping. By means of example one can use tent architecture which quite often represents "unique evocative architectural forms which appear delicate, dynamic, glyphic and may act as socially important objects of art-design" [1].

Moreover, the above-mentioned trend can be traced through creation of temporary architectural objects, that is demonstrated at numerous fairs and exhibitions of contemporary architecture. For instance, there is annual festival of architecture called "Arkhstoyanie" that has been taking place at the village of Nikola-Lenivetz since 2005 that attracts young gifted artists and architects who create art objects in line with the agenda of the festival in the natural environment. Over the years the village was surrounded by an expansive art park that was created by professionals in the sphere of contemporary art and architecture. Dozens of similar chamber festivals have been taking place and gaining popularity in Russia annually, testifying to the rising interest of professionals and general public in such forms as architectural objects that are created at the boundary between art and architecture.

It is critical not to shy away from even more crucial temporary objects of architecture that are created within certain programmes on the basis of predetermined set of rules. International fairs and exhibitions, that take place approximately every 5 years, are the biggest architectural festivals in the world. The national pavilions which are erected by each country for the period of not more than 6 months at a time turn out to be the key "objects" at each of the fairs. 


\section{WORLD'S FAIRS}

Architecture of national pavilions is the primary object, exhibited at the World's fairs. It is the way a country decides to express itself via the shape and form of the national pavilion that captures the attention of the guests of a fair. Creative experiments with the forms, application of materials, as well as architectural and artistic image of a country's pavilion at the World's Fair or Exhibition are widely discussed by the professional community and general public. The most interesting "discoveries" resonate with the guests and get vivified in books and architectural guides.

As a general rule each country, participating in the World's Fair, should reveal the exhibition's main theme through architectural and artistic design of its pavilion. In addition, such pavilions are created in order to serve as clear and straightforward image of the host country in the eyes of the international community. This image should incorporate self-identification, cultural aspirations of present and the future and its unique view on the traditions. That is to say that architects tend to apply their vision for the future towards the constructed object by experimenting with geometry of forms and construction materials, while still mainstreaming the accumulated historic experience of their culture.

It is quite often that the design of a pavilion is based on application of one of the national architectural hallmarks, with national ornament being one of the most commonly used. Such approach was quite frequent at Expo-2010: it was applied at construction of the Polish Pavilion with its façade perforated with traditional Polish pattern (architectural bureau "WWA Architect", "Figure $1 ")$. The creators of the South Korean Pavilion at Expo-2010 decided to bedeck its façade with letters of the Korean alphabet, that ranged in size from tiny to colossal, overlaying each other, curving and thus contributing to the formation of the artistic image of the edifice. ("Figure 2").

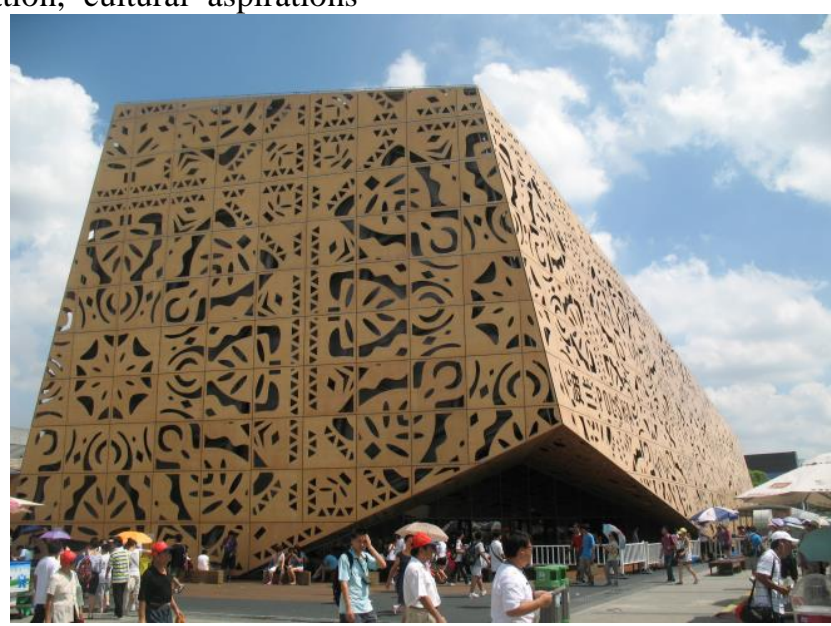

Figure 1 Polish Pavilion at Expo-2010 (author's photo).

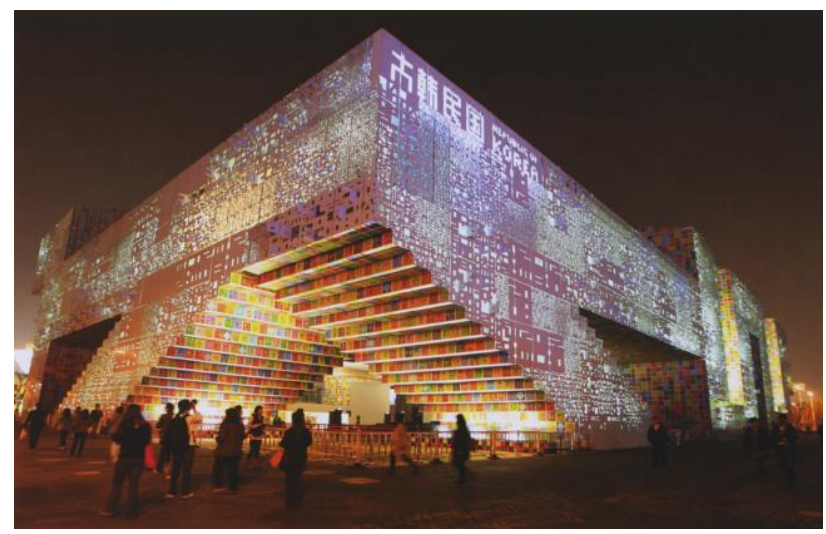

Figure 2 South Korean Pavilion at Expo-2010 (photo from open sources). 
Russian Pavilion consisted of twelve towers, with their top parts perforated on the basis of ethnic ornaments of various ethnic groups living in Russia ("Figure 3"). Therefore, the applied forms of artistic design should allow the guests to grasp the unique national identity of a pavilion. Thus, the artistic image of the edifice gains critical importance, with pavilions constructed for World's Fairs being erected as and perceived as art objects. Such trend can be traced in recent exhibitions.

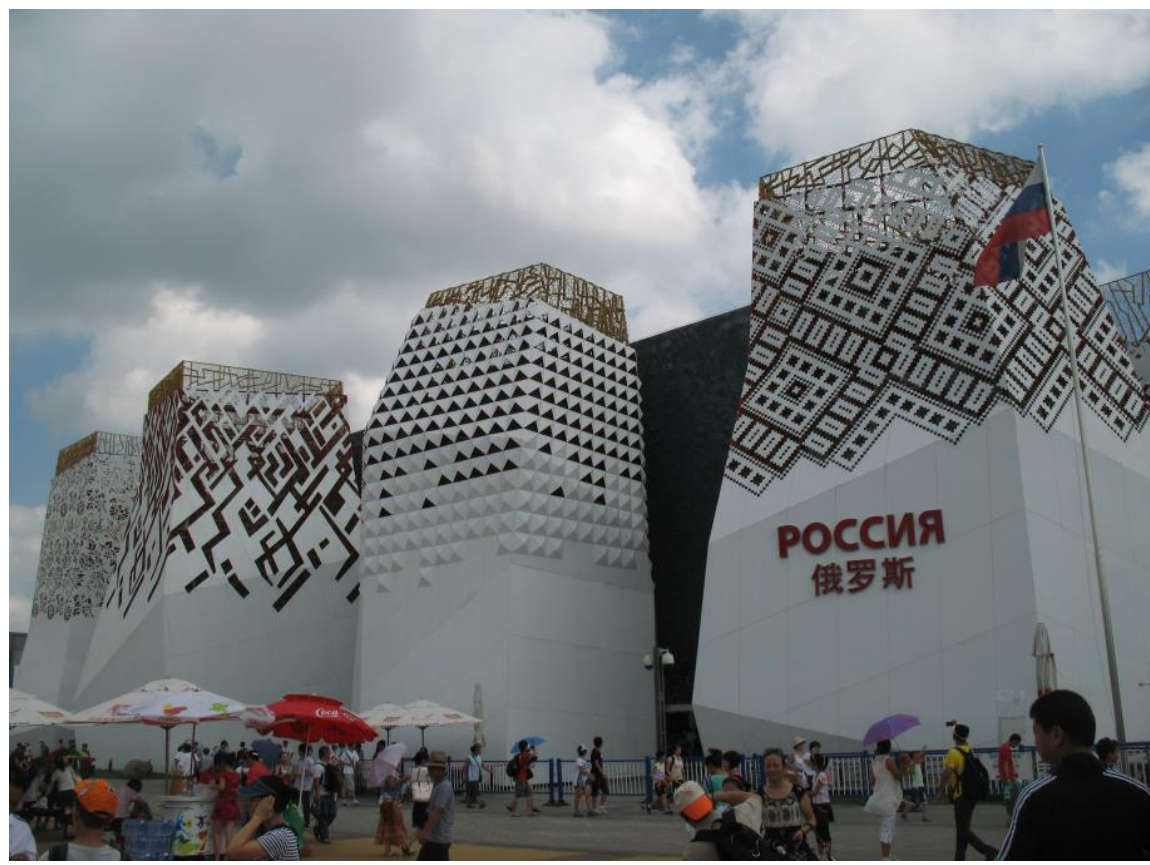

Figure 3 Russian Pavilion at Expo-2010 (author's photo).

The Chinese Pavilion (host-country) became the ultimate centerpiece at the Expo-2010 that took place in Shanghai (China). Towering at 63 meters, this bright-red pavilion occupied the central place at the exhibition and promoted the idea of "Chinese wisdom for urban development" ("Figure 4"). This edifice was named "The Crown of the East" and resembled traditional bright Chinese shrines. The pavilion's creators based their work on the console dougong of the traditional ancient architecture, expanding it to enormous size.

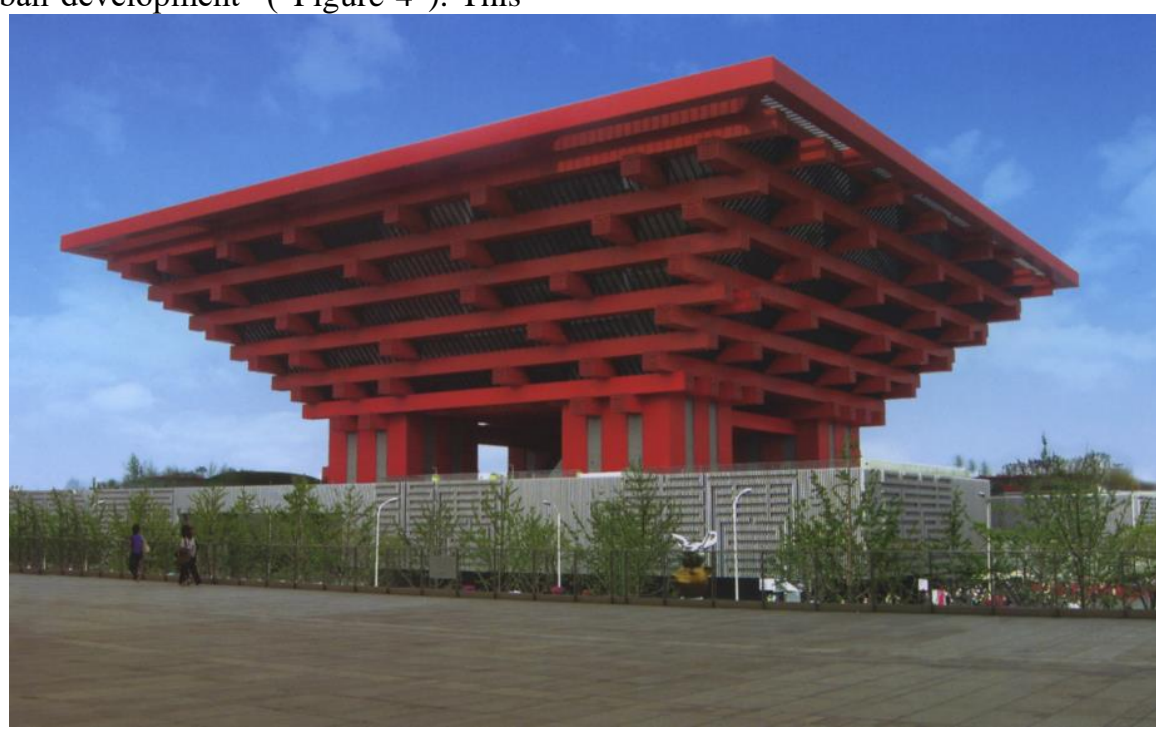

Figure 4 Chinese Pavilion at Expo-2010 (author's photo). 
It is quite often that the creators of the architectural and artistic concept of a pavilion make use of the easily recognizable and perceived symbols making symbolic component the foundation of the artistic image of the edifice. For instance, the foundation of the UAE Pavilion at the Expo-2015 ("Figure 5") was based on the natural form of a canyon, with wall texture mimicking natural sands. Curving walls were called upon to translate the ever-changing shape of the desert dunes.

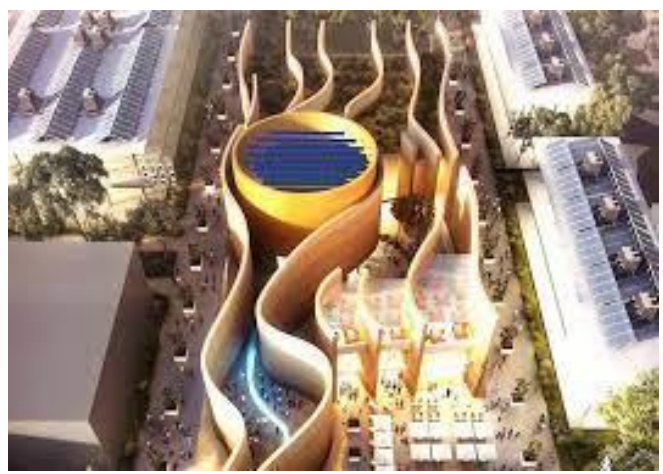

Figure 5 UAE Pavilion at Expo-2015 (photo from open sources).

\section{ARCHITECTURAL EXPERIMENTS OF THE SERPENTINE ART GALLERY}

Since 2000 the Serpentine Gallery has become one of the world's most important focal points of contemporary art. For two decades the worldfamous architectural programme promotes annual construction of a new pavilion at the exhibition territory in Hyde Park in London. World acclaimed architects get invited to contribute to the creation of the new architectural masterpiece. Strict choice of the invited architects, challenging timelines for engineering and construction as well as high requirements to the singularity of design distinguish the Serpentine pavilions from the general line of objects.

The invited architect is given six months to develop the concept and model of the pavilion and to exercise control over its construction so that the new pavilion becomes a valid public space for summer and is generally sold in autumn at a charity auction. Thus, the Serpentine's pavilions originate as temporary objects with the key aim at capturing attention of the guests. Even though the rules require pavilions to be functional (to host lectures, various events and summer cafes) almost none of the invited architects created a space that would represent a building in the common sense. The status of an object (it is said that the mere invitation for an architect to create such a pavilion is equivalent to receiving a professional award), its exclusivity and short life-span become the factors that shift the emphasis in perception and appreciation of the new pavilion. Brightness and extravagance of its visual perception become the key criteria. That is why in this particular case architecture surrenders a number of its inherent properties leaving only artistic expression and transforms into art object. Each of the annually constructed pavilions is definitely an art object that attracts attention of both professionals and general public. This can be testified by Z. Hadid's second pavilion.

Hadid became the first architect to be invited by the Serpentine in 2000, spearheading the launch of the programme, which has over the years evolved and gained international recognition. It also allowed to test its rules and conditions for the construction of pavilions, overall approach and trends for the perception of the programme and artistic approach of the invited architects. The summer pavilion for the Serpentine Gallery constructed by Z. Hadid and P. Schumacher (2007, "Figure 6") was fully in line with the architectural and artistic image and concept in which such pavilions were perceived by the public. The architects created fantastic composition consisting of three gigantic "mushrooms", constructed from the gauze metallic carcass and tautened with fabric. 


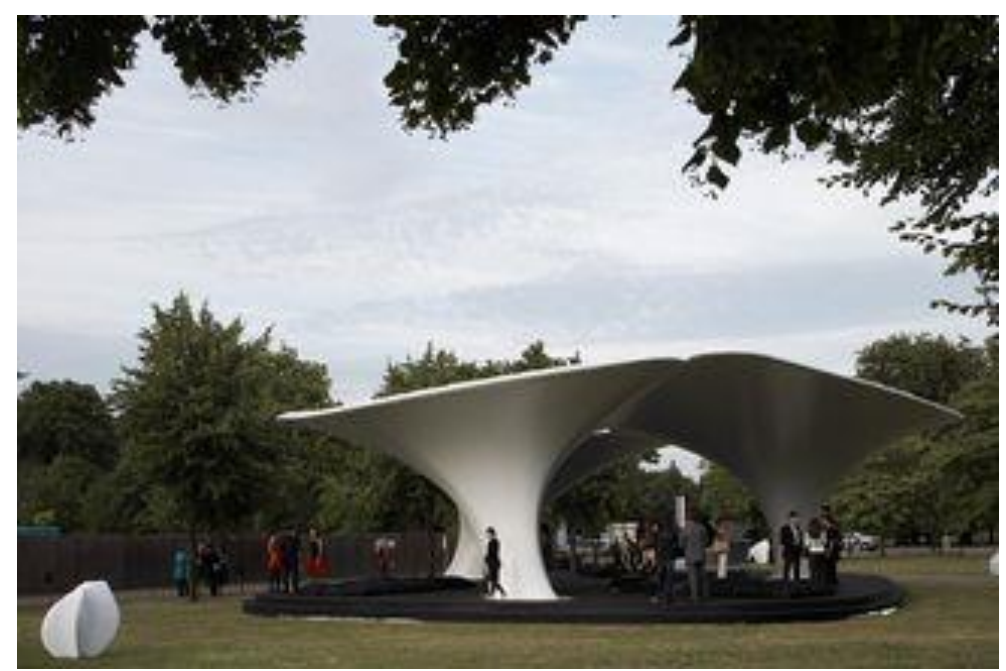

Figure 6 The Serpentine Gallery summer pavilion 2007 (by Z. Hadid, P. Schumacher). Photo from open sources.

Each of the Serpentine Gallery pavilions reflects the style of the architect, his or her message or even the manifest. For instance, the Sou Fujimoto (2013, "Figure 7") pavilion constructed from white metallic rods was designed as fully transparent and permeable structure that radiated enigmatic light at nighttime.

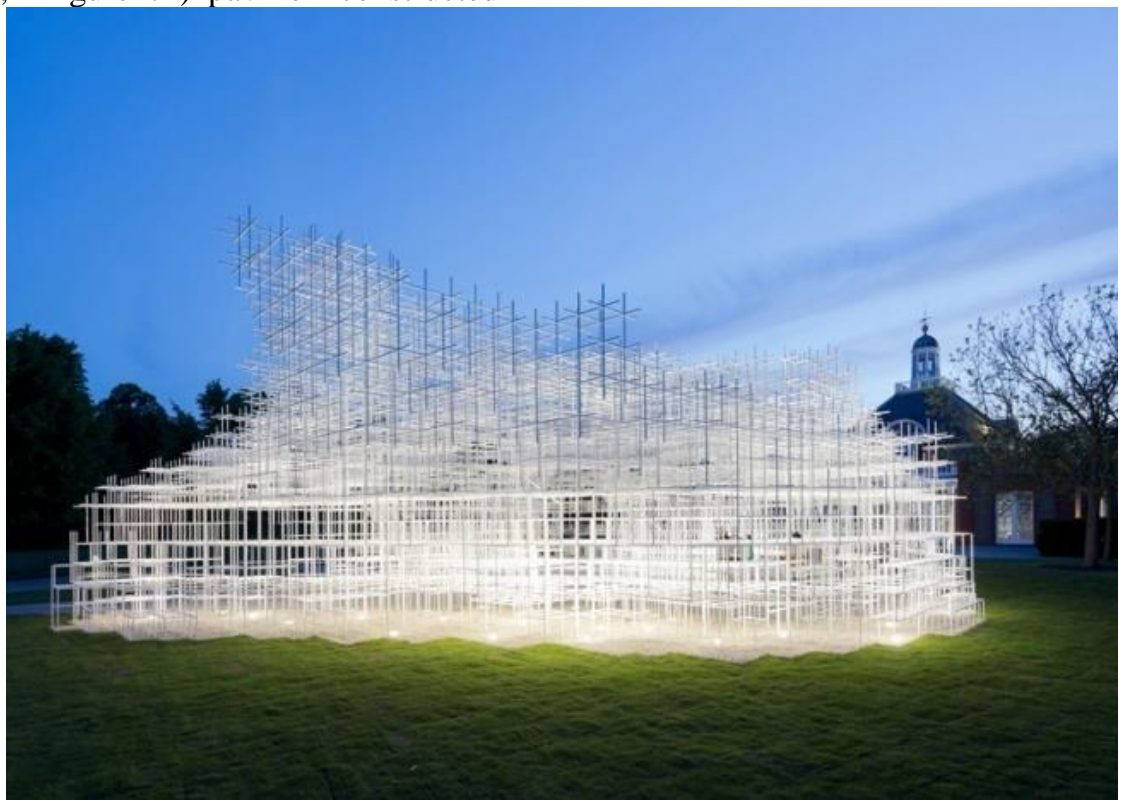

Figure 7 The Serpentine Gallery summer pavilion 2013 (by Sou Fujimoto) @ Iwan Baan.

Looking at the architect's creative work it becomes obvious that he focuses primarily on the creation of objects that stand on the brink between nature and artificial object. He is inspired by natural structures and strives to have them implemented in this work. During the presentation of his pavilion for the Serpentine Gallery, Fujimoto refereed to it as "architectural landscape" [2]. One might notice the combination of natural forms and architectural geometry in the frame of the semi-transparent pavilion with irregular shape and porous structure.
The master views such architectural forms as basic, "formless form" or "unintended space" [3]. Absolutely permeable nature of an object that blurs the boundaries between the internal and external space are one of the most cherished peculiarities of Fujimoto's art. The architect has already constructed fully open and even transparent objects (including residential premises) in Japan.

Thus, any architect that embarks on the creation of a new pavilion for the Serpentine Gallery does not have to build a purely utilitarian edifice while 
still being able to exercise certain functions for a short period of time. Just on the contrary, one can notice studious non-functionality of the pavilions which key aim is to become right and memorable art object.

\section{4. "PICTURESQUE" ARCHITECTURE}

F. Hundertwasser, who came into the field of architecture from being an artist, managed to put in motion his most ambitious ideas and gain international credence. He had an elaborate vision of architecture as fantastic world, bred by his brave and vivid imagination. By creating buildings with various purposes (living premises, kindergartens, hospitals, cultural establishments and places of worship) Hundertwasser promoted bright ornamentality and decorativeness, underlying the inherent connection of his masterpieces with nature. Hundertwasser's objects boast of having acute artistic nature and are characterized by expressivity and abstraction and rejection of straight lines. Hundertwasser scholars emphasize "deep artistic foundation, that elevates [his] architecture to the level of high-quality art" [4]. Clearly, Hundertwasser approached profound architects and engineers for his layout designs, concentrating himself on the development of the basic vision for the object and its artistic image.

All pictorial and architectural masterpieces are called to arouse strong emotions. They contain colours of all specters and fanciful curves. His first major architectural work is the well-known Hundertwasser Haus (Wien, Austria, 1986, "Figure $8 ")$. Is characterized by vivid colouring of the façade. Generally, he applied colouring as "crucial non-constructure mean of overcoming of the "sterility" and monotonous nature of the architectural environment [5] and used elements of structure transformed into real masterpieces: semicircle balconies that resembling bird nests, traceried lantern consoles.

"Die Gruene Zitadelle" (Magdeburg, Germany, 2005 "Figure 9") residential complex is distinguished by unconventional colouring, curving walls and massive planting, with its small towers decorated by golden balls. These artistic principles of the architect are non-negotiable and are endemic to each and every of its masterpieces, always contradicting the deliberate austerity of the traditional city streets.

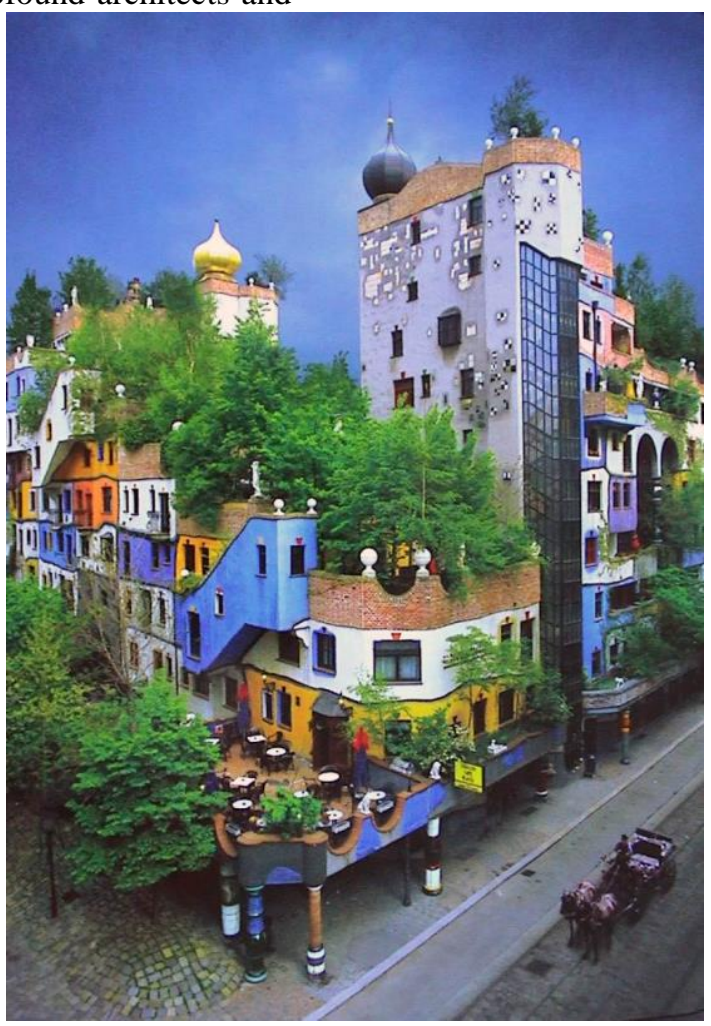

Figure 8 Hunderwasser Haus, Wien. 


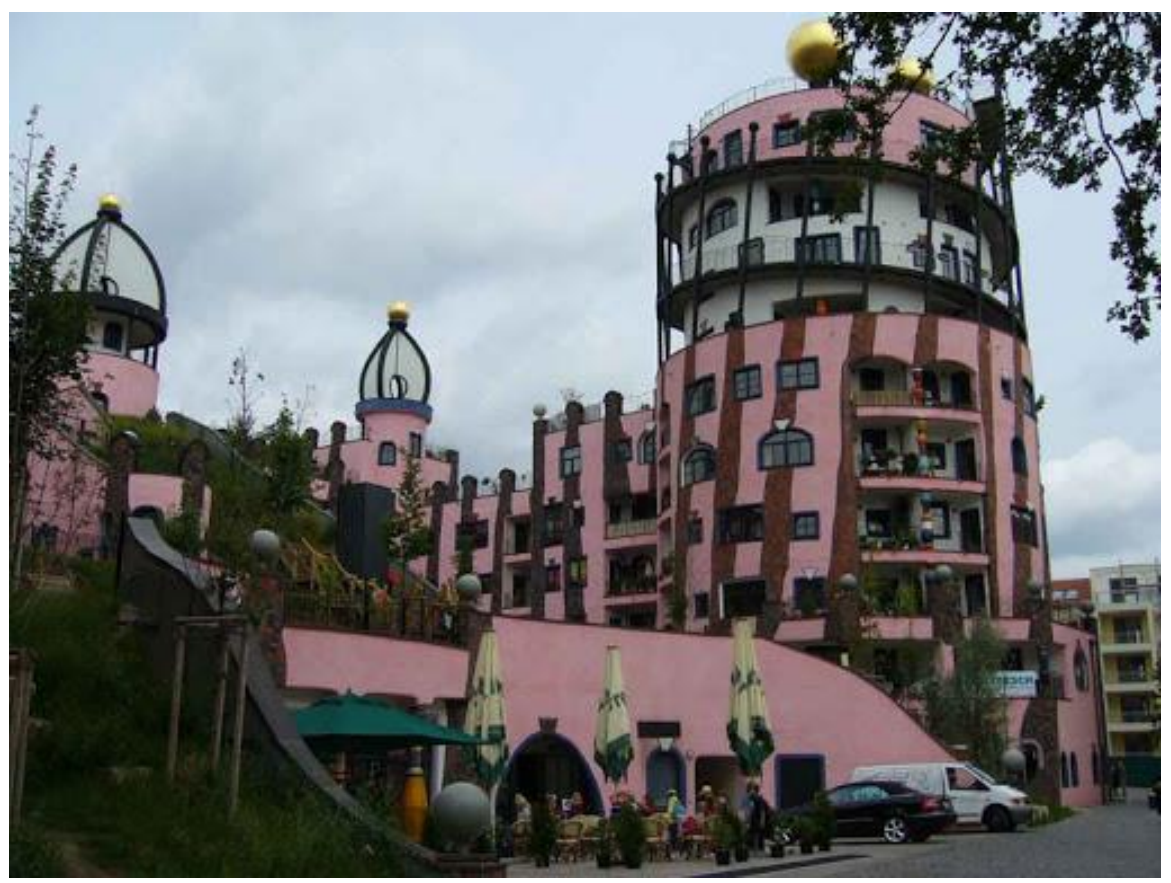

Figure 9 "Die Gruene Zitadelle" residential complex.

All Hundertwasser architectural pieces are characterized by asymmetry and motives of nature. They have a key peculiarity - while each window has its own life and artistic expression, they are united to become the pillar of the artistic image of the building [6]. Hundertwasser was of opinion that the correct house should be composed of windows, while all space between them should be used as canvas for colouring as one might consider fit. He even claimed that windows "have the inherent right to self-identification" [7]. That is why it is impossible to find two similar windows in Hundertwasser's buildings, as they would inevitably differ in shape, configuration, colouring and decoration.

As there is hardly anything identical in nature, the "Die Gruene Zitadelle" does not have identical windows, columns, doors or even door-handles. While creating his masterpieces, the artist generally used natural materials, decorated buildings with natural stones and ceramics, seasoning it with natural greenery and bright colours. It is impossible to define the shape of the building. Though it fits into the square land plot, Hundertwasser (being faithful to his vision) embodied the edifice with his dream of a house without straight angles accompanied by complex and dynamic decoration of the façade.

The number of storeys in the building tends to rise or plummet depending on the side. The volumes and spaces of the edifice translate into each other. The roof in its turn, became multilayered with green lawn and a garden. Many of the trees planted on the roof are no rooted into the external walls of the building and even peer out of windows. All these subtle natural peculiarities accompanied by the artistic image translate a totally fantastic perspective.

Illusiveness, which was the most favourite tool of the master, has the most vivid revelation. The design of the façades of the building creates the impression of total absence of flat surface. The edifice is teeming with artistic and optical effect. The main tower of the "Die Gruene Zitadelle", though round in shape, appears slightly tilted due to optical effect that is achieved through series of brown lanes of planches that ascend with heavy gradient. The impression is further aggravated through timber cover that tilts and spirals around three top floors of the building. Finally, thin timber pillars that function as the foundation for all of the timber cover also have certain tilt supporting the illusion of the falling tower.

Hundertwasser paid special attention to the composition, picturesque distinctiveness and emotional perception in his architectural masterpieces. Thus, his architecture consistently reflects all aspects of the author's philosophy, as he considered himself to be adversary of rationalism and academic austerity. He managed to create 
bright and fantastic world in each of his works, that stand in contrast with the surrounding urban environment, both historic and modern. The artistic nature of his buildings undoubtedly occupies forefront of his works, being the key aim and concern.

\section{INTERIOR ARCHITECTURE}

It is not uncommon that architect cannot fully develop the exterior of his or her piece of art. In such cases interior architecture design becomes the only viable option, as its artistic style can compensate the meager facades or its total absence. The Starbucks coffeeshop (2011, arch. K. Kuma) which was supposed to be constructed on the small historic street of Fukuoka can be considered a worthy example. The real estate development of the

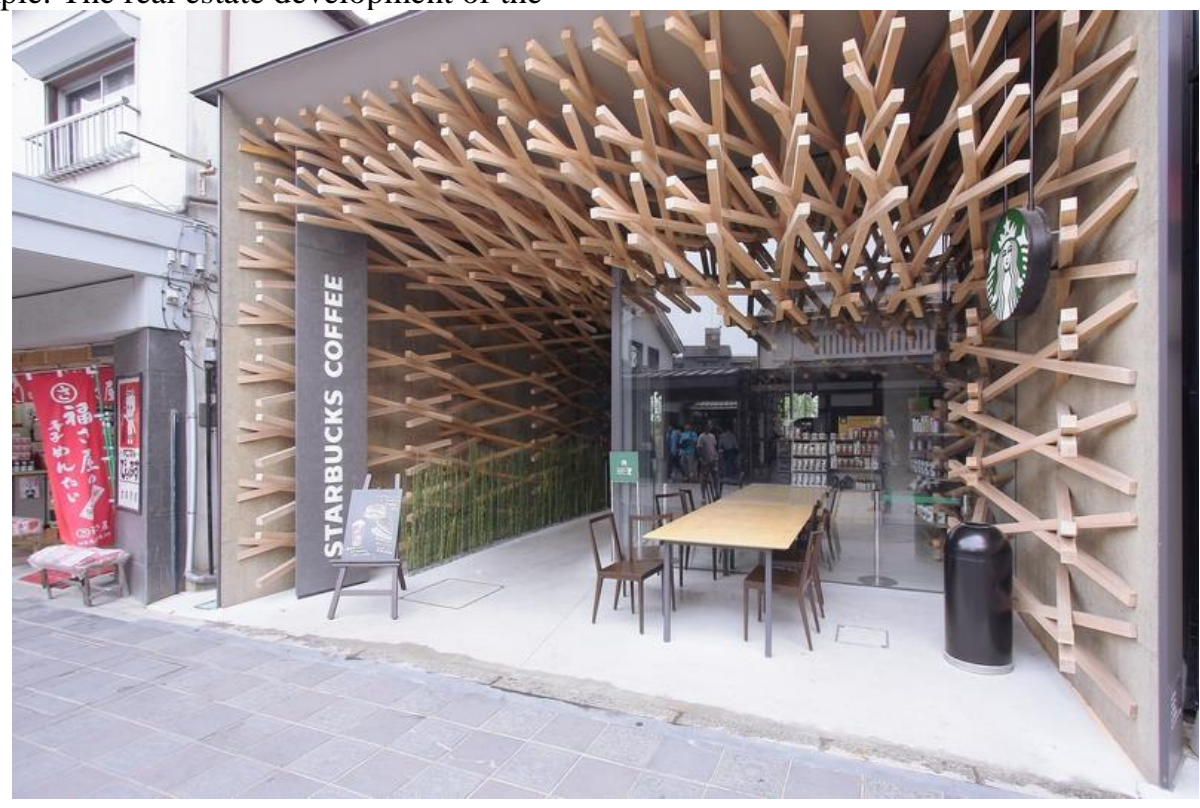

Figure $10 \quad$ K.Kuma Strabucks Coffeeshop. (Photo from open sources).

The interior decoration was imbued with the sense of the Japanese minimalism, captures attention of the passers-by, luring them into the internal space that was created by the creative vision of the great architect. Multidimensional structure of timber rods became the key signature spot and the foundation of the interior design.it was applied to the ceiling and the right wall of the building, contributing to the sense of depth and complexity. Each of the rods had length between $1.3-4$ meters and $6 \mathrm{~cm}$ in square section.

Timber rods connection method was the most complex detail of the project. The geometry of lines formed by the rods was supposed to create the sense of space fluidity at the same time retaining street was represented by the traditional Japanese one and two-story buildings. Such neighborhood led to the creation of a one-story coffeeshop while the necessity to fit into the street's tight built-up accounts for its extremely simple form of elongated parallelepiped.

In addition, there was a small garden adjacent to the premises of the coffeeshop, which had special importance for the town and incorporated camphor laurel and plum trees. It was decided to retain the garden and convert it into the terrace for the visitors. Acute laconic design of the exterior of the coffeeshop was balanced by the unexpected and intriguing architectural solution of the interior which was expanding into the street almost without having an actual façade. ("Figure 10") 
slashes was driven by the fact that the rods were supposed to be tightly attached. A slight tilt in the toe-hold provided for ideal balance of visual proportions. This project saw implementation of the Japanese ancient timber construction methods in accordance with which tight connection of items supported by tiny plays in joints provide for absorption of potential deformations.

Kengo Kuma decided to take the whereabouts of the world famous coffeeshop as the foundation of the project. This allowed to have its spacing interpreted as seamless transition from the busy street to a green oasis. Creation of an art object that would not conflict with the complex and valuable historic surroundings was another pillar of the project. Timber rods, that dominate the interior of the coffeeshop, project into the street, reminding the passers-by of the wood branches and chiming with the ancient camphor trees of the nearby Dazaifu Tenman-gu Shrine.

Use of properly finished yet unpainted timber in the construction of the coffeeshop is fully in line with the Shinto aesthetics, representing harmonic interaction between ancient traditions and modern technologies.

\section{CONCLUSION}

Examples tackled in this article (which represent only a small portion of a vast array of modern buildings) expound upon the current trend when edifices of contemporary architecture exercise the function of art objects. Having been revealed in the last decade of the XX century, this trend can be considered as being a well-established direction of contemporary architecture in the XXI century.

The essential shift towards prevalence of creative aspect occurs in the very nature of architectural art. Materials, geometry and masked elements are used to emphasize artistic (not construction features or spacing) properties, becoming the primary characteristics of the object.

The article identifies general types of architecture which are prone to such essential shift due to their inherent expository nature - primarily, temporary architectural objects like pavilions at International Fairs and Exhibitions or summer pavilions of the Serpentine Gallery.

In case of permanent pieces of architecture such objects tend to enter into an active discussion with the environment by either contrasting or indulging in polemics with it in each particular instance. Nevertheless, such object transforms into an artistic focal point in urban environment. These are only the situations when artists create the art space within the interior that could be viewed as exception. Therefore, such objects cannot be identified ab extra and would reveal their artistic properties and merits only to the guests.

\section{AUTHORS' CONTRIBUTIONS}

This paper is independently completed by Nina Konovalova.

\section{REFERENCES}

[1] E.V.Chrenikova, O.V. Myskova. Tent architecture as an object of art-design. Collected works "Design and art - strategy of project culture of the XXI century",- M., 2019. p.82.

[2] https://www.serpentinegalleries.org/whatson/serpentine-gallery-pavilion-2013-soufujimoto/ (dd 29.06.2021).

[3] History of Sou Fujimoto, told by himself // Internet journal «Berlogos», July 7th 2016 г. Electronic source. Access regime: http://www.berlogos.ru/article/istoriya-sufudzimoto-rasskazannaya-im-samim/ (dd. 01.07.2021)

[4] V. B. Polyakov. «Picturesque» architecture of Friedensreich Hundertwasser // Files from the international science conference "Science, education and experimental engineering". Collected works. 2014. p.125.

[5] G.N.Kuznetsova. Friedensreich Hundertwasser (1928-2000) On plasticity, new rhythmic structures, urban colouring // Decorative art and object and spatial environment. Vestnik ща Stroganov Moscow State University of Arts and Industry, №1, 2015. p. 31-39.

[6] N.A. Konovalova. Hundertwasser. «DirectMedia» Publishing house, 2015.

[7] E. Zemnitsky. The Realm of Magic Mirrors. // Around the world, M., 2006. Electronic sources. Access regime: https://www.vokrugsveta.ru/vs/article/207/ (dd 03.07.2021) 